\title{
Resistance to Reform: Reconsidering the
}

\section{Role of Individual-Specific Uncertainty}

by

Antonio Ciccone*

27 February 2001 (First Version: 4 March 1998)

\begin{abstract}
Individual-specific uncertainty may increase the chances of reform being enacted and sustained. Reform may be more likely to be enacted because a majority of agents might end up losing little from reform and a minority gaining a lot. Under certainty, reform would therefore be rejected, but it may be enacted with uncertainty because those who end up losing believe that they might be among the winners. Reform may be more likely to be sustained because, in a realistic setting, reform will increase the incentives of agents to move into those economic activities that benefit. Agents who respond to these incentives will vote to sustain reform in future elections, even if they would have rejected reform under certainty. These points are made using the trade-model of Fernandez and Rodrik (AER, 1991).
\end{abstract}

Keywords: Status-quo bias, Bias against reform, Individualspecific uncertainty.

JEL Classifications: D72, D74, D81.

* Universitat Pompeu Fabra. I would like to thank Reza Baqir, Antonio Cabrales Brad DeLong, Giovanni Peri, David Romer, Ilya Segal, two referees and an editor for their comments. 


\section{Introduction}

Why do governments so often fail to adopt economic policies that economists consider efficiency-enhancing? This is the question addressed in an influential paper by Raquel Fernandez and Dani Rodrik (1991). They argue that one of the reasons why governments often dismiss reform is that individual winners and loser cannot be identified beforehand. This generates individual-specific uncertainty which leads to a bias against efficiencyenhancing economic policies and towards the status quo.

Fernandez and Rodrik (FR) first illustrate their point using an example and then develop it more precisely using a trade-model which, they argue, generalizes their example and puts it into a general-equilibrium context. The basic point of their introductory example can be easily illustrated by the following (somewhat different but simpler) example. Assume that there is an economic policy which, if put into place, increases the income of a fraction $0<a<1$ of the population by an amount equal to $g>0$ and decreases the income of all others by an amount $l<0$. Suppose that the policy is adopted if a majority votes in favour and rejected otherwise. These assumptions combined imply that if all individuals know whether they will gain or lose at the time they vote-i.e. there is no individual-specific uncertainty - then the new economic policy will be supported by a fraction $a$ of voters and enacted if and only if $a \geq 1 / 2$. Now suppose that people do not know with certainty whether they will gain or loose at the time they vote-i.e. there is individual-specific uncertainty. Instead, voters only know that a fraction $a$ of them will gain $g>0$ while all others will loose $l<0$, and they therefore conclude that the probability $p$ of being among the winners is equal to $a$. Consequently, risk-neutral agents will vote in favour of the policy if and only if their expected gain $\pi=a g+(1-a) l$ is positive. This implies that support for the economic policy in this static example may be greater or smaller with individual-specific uncertainty than without. In particular, support for the policy will be greater (smaller) with individual-specific uncertainty than without if the expected gain is positive (strictly negative). The economic policy may therefore be enacted with individualspecific uncertainty in cases it would have been rejected without and vice-versa. FR find exactly the same result in their static example and therefore conclude that, in a static scenario, individual-specific uncertainty does neither generate a bias against reform nor lead to an asymmetry between the case with individual-specific uncertainty and the case without. 
FR argue that an asymmetry between these two cases will, however, arise naturally in a dynamic, two-period model. To see why suppose that the economic policy is put to vote twice: in the beginning of the first period and, again, in the beginning of the second period. Assume also that those who will gain $g$ in each period where the economic policy is in place are a fraction $a$ of the electorate. All remaining voters will lose $l<0$ in each period where the economic policy is in place. Finally, suppose that there are no costs of enacting or reversing the policy and that voters apply a discount rate $\delta \geq 0$ to second period payoffs. Consider first the situation where voters know in the beginning of the first period whether they gain or loose from the economic policy. In this case, the following equilibria emerge. If $a \geq 1 / 2$, then voters anticipate that the policy will be passed in the beginning of the second period whether or not it has been passed in the beginning of the first period. This implies that a fraction $a \geq 1 / 2$ of voters know that their discounted gain of the economic policy being enacted in the beginning of the first period is $(1+\delta) g$. Consequently, the policy will be enacted in the first period and sustained in the second period. If $a<1 / 2$, however, then the policy will be rejected in the beginning of the first period and rejected again in the beginning of the second period. The situation is somewhat more complex in the case with individual-specific uncertainty. In the beginning of the first period, voters only know the fraction of people who will gain or loose from the policy but not whether they will be among the winners or losers. They also realize, however, that if the policy is put into place during the first period, then everybody finds out about being either a winner or loser and votes accordingly when trade-reform is put to vote again in the beginning of the second period. Consequently, voters anticipate in the beginning of the first period that if the economic policy is enacted, then it will be sustained in the election in the beginning of the second period if and only if $a \geq 1 / 2$. Hence, if $a \geq 1 / 2$, then voters know that their expected discounted gain of the economic policy being enacted in the beginning of the first period is $(1+\delta) \pi$. If $a<1 / 2$, on the other hand, then voters know that their expected discounted gain of passing the policy in the first period is $\pi$; this is because the economic policy, if enacted in the first period, will not find enough support to be sustained in the beginning of the second period. Combining these two cases yields that if voters are risk-neutral, then the policy will be enacted in the beginning of the first period if $\pi \geq 0$ (and be sustained in the beginning of the second period if and only if $a \geq 1 / 2$ ) and rejected in the beginning of the first period if $\pi<0$. If the economic policy is rejected in the beginning of the first period, then it will be rejected again in the beginning of the second period as no new information about the identity of winners and losers becomes available. The next table summarizes all equilibria.

Table 1: Equilibria in the Two-Period Example 


\begin{tabular}{|l|l|l|l|l|}
\hline \multirow{2}{*}{} & \multicolumn{2}{|c|}{$a \geq 1 / 2$} & \multicolumn{2}{c|}{$a<1 / 2$} \\
\cline { 2 - 5 } & \multicolumn{1}{|c|}{ Period 1 } & Period 2 & Period 1 & Period 2 \\
\hline CERTAINTY & Pass & Sustain & Reject & Reject \\
\hline \multirow{2}{*}{ UNCERTAINTY } & Pass $(\pi \geq 0)$ & Sustain & Pass $(\pi \geq 0)$ & Reject \\
\cline { 2 - 5 } & Reject $(\pi<0)$ & Reject & Reject $(\pi<0)$ & Reject \\
\hline
\end{tabular}

The table illustrates that in the two-period example there is an asymmetry in how individual-specific uncertainty affects economic policies that would have been in place in the second period under certainty compared to how it affects policies that would not have been in place in the second period under certainty. If an economic policy would not have been in place in the second period under certainty, it will not be in place with individualspecific uncertainty. On the other hand, if a policy would have been in place in the second period under certainty, it might not be in place with individual-specific uncertainty. This is the asymmetry that FR argue explains why individual-specific uncertainty works against efficiency-enhancing policies in a dynamic scenario. In fact, Table 1 shows that this asymmetry implies that the policy is less likely to be in place in the second period with individual-specific uncertainty than without. ${ }^{1}$

It is interesting to note, however, that individual-specific uncertainty does not work against efficiency-enhancing policies, i.e. reform, in the example of Table $1 .^{2}$ Instead, individual-specific uncertainty only works against economic policies that strictly decrease aggregate income. To see this clearly notice that the policy is less likely to be in place with individual-specific uncertainty than without because if $\pi<0$, then the economic policy is rejected in both periods in the case with individual-specific uncertainty even if $a \geq 1 / 2$. Moreover, $\pi<0$ if and only if the policy strictly decreases aggregate income, i.e. $a g+(1-a) l<0$. Hence, the economic policy is less likely to be in place with individualspecific uncertainty than without only because, with individual-specific uncertainty, it will be rejected if it strictly decreases aggregate income. Individual-specific uncertainty

\footnotetext{
${ }^{1}$ There is an alternative reading of FR's use of the "asymmetry", "bias towards the status-quo", and "bias against reform" introduced by individual-specific uncertainty. This reading is that they only refer to following two facts: (I) with individual-specific uncertainty, reform may be enacted in the first period and revoked in the second period, while reform will always be sustained if enacted under certainty; (II) reform will be rejected in the second period if rejected in the first period whether or not there is individual-specific uncertainty. This definition implies that, as long as (I) and (II) hold, individual-specific uncertainty will introduce a bias towards the status-quo in the "alternative FR sense" even if the status-quo is overturned for a set of model-parameters that have $99 \%$ probability with individual-specific uncertainty but only $1 \%$ probability under certainty. Similarly, individual-specific uncertainty would introduce a bias against reform in the "alternative FR sense" even if reform is enacted and sustained for parameters that have $99 \%$ probability with uncertainty but only $1 \%$ probability under certainty.

${ }^{2}$ Reform is defined as a change for the better or an improvement in the $4^{\text {th }}$ Edition of The American Heritage Dictionary of the English Language.
} 
therefore only works against change to the worse. If the economic policy results in a change to the better-i.e. increases aggregate income - then the policy is as likely to be in place in the second period in the case with individual-specific uncertainty than in the case without. Combined, these last two results yield that enacted economic policies are strictly more likely to increase aggregate income with individual-specific uncertainty than without. ${ }^{3}$ Individual-specific uncertainty therefore decreases the probability that efficiency-enhancing policies are enacted but, at the same time, increases the probability that enacted policies are efficiency-enhancing in the example in Table 1.

The result that individual-specific uncertainty only works against economic policies that strictly decrease aggregate income is the main difference between the example in Table 1 and a two-period version of FR's introductory example. In a two-period version of their example, individual-specific uncertainty will work both against policies that decrease aggregate income and policies that increase aggregate income. Hence, in their example, enacted policies will be less likely to increase aggregate efficiency with individual-specific uncertainty than without if and only if the probability of uncertainty leading to the rejection of efficiency-enhancing policies is greater than the probability of uncertainty leading to the rejection of policies decreasing aggregate efficiency.

FR argue that their introductory example does not address key-questions like, for instance, the source of uncertainty and general-equilibrium aspects of policy-change. Moreover, they are interested in applying their argument to trade-reform. They therefore elaborate on their point by developing a two-period, two-sector trade-model where workers vote on trade-reform in the beginning of each period and decide whether to switch sector immediately afterwards. The most important difference between FR's trade-model and their introductory example is that, in their trade-model, reform affects not only payoffs but also the economic environment and hence individual economic behavior. The objective of the remainder of this paper is to show that, as a result, second-period reform may be in place in FR's trade-model in the case with individual-specific uncertainty, even if it would have been rejected in both periods under certainty. This stands in contrast to the main result of a two-period version of their introductory example; there, reform would always be revoked in the second period in the case with individual-specific uncertainty if it would not have been enacted under certainty. To use FR's terminology, the remainder of this paper shows that, in their two-period trade-model, individual-specific uncertainty does not generate any asymmetry between the case where second-period trade-reform would be in place under certainty and the case where second-period trade-reform would not be in place

\footnotetext{
${ }^{3}$ This is because, with individual-specific uncertainty, all enacted policies increase aggregate income while some of the policies enacted without individual-specific uncertainty will decrease aggregate income.
} 
under certainty. Consequently, it cannot be shown that individual-specific uncertainty leads to a bias against trade-reform in their two-period model.

The most important (but not the only) reason why FR's trade-model yields that second-period reform may be in place in the case with individual-specific uncertainty, even if it would have been rejected in both periods under certainty, is straightforward. If there is individual-specific uncertainty and reform is enacted in the first period, then support for sustaining trade-reform in the beginning of second period (when all individual-specific uncertainty has been resolved) will be greater than support for enacting reform in the first period under certainty; for comparison, in a two-period version of FR's introductory example as well as the example in Table 1, second-period support for a reform enacted in the first period with individual-specific uncertainty will be identical to support for the policy in the first period under certainty. This feature of FR's two-period trade-model implies that reform may find enough support to be sustained in the second period, even if it would not have found enough support to be enacted in the first period had there been no individualspecific uncertainty. The intuition for this result is simple. Once trade-reform has been enacted, some of the workers who would have voted against it under certainty will nevertheless switch to the sector that gains (even if they have not incurred any sunk cost). These workers will vote against revoking trade-reform in the future. This argument applies to any type of reform. In a realistic setting, reform will increase the incentives of economic agents to move into those economic activities that benefit from the new economic policies. If some agents respond to these incentives, then support for sustaining reform in future elections (when individual-specific uncertainty has been resolved) will be greater than support for enacting reform in the case without individual-specific uncertainty.

This explains why reform, once enacted, may persist in the case with individualspecific uncertainty, even if it would have been rejected in both periods under certainty. But will trade-reform ever be enacted in the case with individual-specific uncertainty if it would have been rejected under certainty? There are two reasons why this may be the case in FR's trade-model. The more realistic one is that a majority of workers may end up losing a little from reform and a minority gaining a lot; this implies rejection by a majority under certainty but acceptance with individual-specific uncertainty if those workers who will end up losing a little believe that there is a chance of them being among the winners. The second and more interesting reason is that workers actually like individual-specific uncertainty. This is because they enjoy the upside potential of the uncertainty without having to bear the downside risk as they always have the option of staying in the sector they worked in originally should they find out that their uncertain net income in the sector gaining from reform is too low. 
To be more precise assume, like FR, that workers are risk-neutral and that individual-specific uncertainty arises because they will find out about their cost of switching to the sector gaining from trade-reform only after reform has been passed for the first time. Clearly, this implies that workers will only change sector if their switching-cost turns out to be below some threshold; if the cost is high, workers will simply stay in the sector they worked in originally. Workers' payoff if trade-reform is enacted is therefore a convex function of their switching-cost. Hence, assuming that workers know the distribution of switching-costs in the population, their expected utility of enacting trade-reform may be positive, even if ex-post utility is negative for more than half of the values of the switchingcost (Michael Rothschild and Joseph Stiglitz (1970)). Trade-reform may therefore be enacted with individual-specific uncertainty, even if it would have been rejected by a majority had workers known their switching-cost. Moreover, trade-reform may be enacted with individual-specific uncertainty even if it would have been rejected by a majority had workers known their switching-cost, because the median of the switching-cost may be higher than its expected value. The reasons why, in FR's trade-model, reform once enacted may be sustained in the second period (when workers have found out about their switchingcost), even if it would not have been enacted had workers known their switching-cost, are twofold. The more interesting reason is that, in the case with individual-specific uncertainty, some of the workers who would have voted against enacting trade-reform had they known their switching-cost, will nevertheless go to work in the sector that gains in the first period and vote against revoking trade-reform in the second period. These workers would have voted against trade-reform had they known their switching-costs in the beginning of the first period, because they prefer to stay in the sector they work in before reform at before trade-reform prices rather than work in the sector that gains from reform at after trade-reform prices. Once trade-reform has been passed, however, workers will compare working in the two sectors at after trade-reform prices. As reform implies that relative prices change in favour of the sector that gains, switching becomes relatively more attractive after trade-reform is in place. To complete the argument it is important to note that workers will not consider the effect of their first-period switching-decision on voting outcomes as they anticipate that their individual vote is inconsequential for trade-reform being sustained or revoked in the future. A second, less interesting reason why tradereform may be sustained in the second period in FR's trade-model, even if it would not have been enacted in the first period had voters known their switching-cost, is that FR assume that there may be a sunk-cost of switching sector. 
The main point made in this paper is related to the literature on policy persistence and the recent work by Coate and Morris (1999). ${ }^{4}$ Like this paper, Coate and Morris (CM) emphasize that " $[w]$ hen an economic policy is introduced, agents will often respond by undertaking actions in order to benefit from it. These actions will translate [...] into political pressure to retain the policy [...]." There are, however, major differences between the present paper and FR on the one hand and CM on the other. First, CM suppose that voters do not decide directly on the policy; instead, decisions are taken by an elected politician. Second, they assume that the policy only benefits politicians and firms but not voters (who would therefore always reject the policy if they were to vote on it directly). Third, CM assume that firms have to incur a switching-cost every time they change sector (while the present paper allows for the case where workers can switch back to the sector they worked in originally at no cost). Most importantly CM address a different question than FR and the present paper. FR and the present paper ask whether efficiency-enhancing policies are more or less likely in the presence of individual-specific uncertainty than in the case where everybody is certain about the policy's consequences. CM analyze the question of policy-persistence without addressing or modeling the role of individual-specific uncertainty, focusing instead on the persistence of policies that may increase the income of a corrupt politician but decrease welfare of voters in general.

\section{$2 \quad$ A Model of Trade-Reform}

FR discuss the role of individual-specific uncertainty for trade-reform in an open, perfectly competitive, two-sector economy. They present both a one and two-period model, which will be discussed in detail in the next two sections.

\subsection{The Static Model}

There are two sectors, $X$ and $Y$, that produce different goods with constant-returns-toscale technologies using labor only. Wages and prices are expressed in terms of good $Y$. Before trade-reform, wages are identical in both sectors. Workers in the economy are considering whether to support a trade-reform that will leave the sector- $Y$-wage $w_{Y}$ and the wage in sector $X$ in terms of good $X$ unchanged but increase the price of good $X$ and hence the sector- $X$-wage $w_{X}$ in terms of good $Y$. Once trade-reform is passed, workers can switch between sectors at a cost that comes in two parts: a part common to all workers that must be paid if workers want to have the option of switching sector, and an

\footnotetext{
${ }^{4}$ See also Brainard and Verdier (1994) and Rodrik (1991).
} 
individual-specific part that workers only have to pay if they actually switch. ${ }^{5}$ Trade-reform is passed if and only if more than half of all workers vote for it. Workers know the cost $\theta \geq 0$ they have to incur to have the option of switching when they vote. Regarding the individual-specific cost $c_{i} \geq 0$ that workers only have to pay if they actually switch, FR discuss two cases: (I) workers know this cost when they vote; (II) workers find out about this cost only after trade-reform is passed (if they paid $\theta$ ) and therefore face individualspecific uncertainty when they have to vote. When there is individual-specific uncertainty, it is such that workers only know the distribution of individual-specific costs among workers in their sector. ${ }^{6}$ All workers have identical preferences and vote for trade-reform if and only if it increases their (expected) utility. Their utility function is $v\left(P_{X}\right) I$ where $I$ is the wage in terms of good $Y$ and $v\left(P_{X}\right)$ is strictly decreasing in $P_{X}$.

How will uncertainty about individual-specific costs of switching between sectors affect workers' vote on trade-reform? It is clear that workers initially in sector $X$ will vote for trade-reform and stay in sector $X$ if trade-reform is passed whether or not there is individual-specific uncertainty ex-ante. This is because their wages remain constant in terms of good $X$ and increase in terms of good $Y$, while the wages of workers in sector $Y$ remain constant in terms of good $Y$ and decrease in terms of good $X$.

The key-question is therefore whether workers initially in sector $Y$ will vote for or against trade-reform. To answer this question in the case with individual-specific uncertainty, suppose that trade-reform has been passed and consider workers $i$ in sector $Y$ who have incurred $\theta$ and found out about their individual-specific cost of switching $c_{i}$. These workers must now decide whether to incur $c_{i}$ to actually go to work in sector $X$. Evidently, they will, at this point, switch to sector $X$ if and only if the resulting wageincrease is greater than their individual-specific cost of switching. This implies that their end-of-period payoff would be

$$
V_{U}^{+}\left(c_{i}\right)=v\left(P_{X}^{+}\right) \operatorname{Max}\left\{w_{X}^{+}-\theta-c_{i}, w_{Y}-\theta\right\},
$$

where $P_{X}^{+}$and $w_{X}^{+}$denote the price of good $X$ and the wage in sector $X$ after tradereform. The end-of-period payoff of workers initially in sector $Y$ if trade-reform is rejected is $V^{*}$

$$
V^{*}=v\left(P_{X}^{*}\right) w_{Y},
$$

\footnotetext{
${ }^{5}$ FR interpret the common cost as a sector-specific human-capital investment that must be made to be able to switch sector and the individual-specific cost as capturing sector-specific productivity-differences.

${ }^{6}$ There is a slight ambiguity in FR on whether workers know the distribution of individual-specific costs among the whole population or among workers in the their sector. Implicitly they are assuming that workers know the distribution among workers in their sector.
} 
where $P_{X}^{*}$ denotes the price of good $X$ before trade-reform. Recall that in the case with individual-specific uncertainty about switching-costs at the time workers have to vote, it is assumed that workers only know the distribution of $c$ among workers in their sector. All workers in sector $Y$ are therefore identical ex-ante. Their expected utility from tradereform in the case with individual-specific uncertainty at the time they have to vote is therefore $E V_{U}^{+}(c)$ if they plan to incur $\theta$ after reform is passed; the expectation is taken using the distribution of $c$ among workers in sector $Y$. Workers in sector $Y$ will consequently vote for trade-reform in the case with uncertainty about individual-specific switching-costs if and only if

$$
V^{*} \leq E V_{U}^{+}(c)
$$

If (3) holds and trade-reform is passed, then workers initially in sector $Y$ will incur $\theta$ and find out about their actual individual-specific cost of switching. If their individual-specific cost turns out to be lower than the wage-increase from switching to sector $X$, they will switch sector. If (3) does not hold, then workers in sector $Y$ will all vote against tradereform.

In the case without uncertainty about individual-specific costs of switching between sectors, the end-of-period payoff of workers initially in sector $Y$ with individual-specific $\operatorname{cost} c_{i}$ is

$$
V_{C}^{+}\left(c_{i}\right)=v\left(P_{X}^{+}\right) \operatorname{Max}\left\{w_{X}^{+}-\theta-c_{i}, w_{Y}\right\}
$$

if trade-reform is passed. The difference between (4) and (1) arises because, in the case without individual-specific uncertainty, workers will incur $\theta$ only if they end up switching sector. Combining (4) with (2) yields that workers initially in sector $Y$ will vote for tradereform in the case without individual-specific uncertainty if and only if their $\operatorname{cost} c_{i}$ satisfies

$$
V^{*} \leq V_{C}^{+}\left(c_{i}\right)
$$

Figure 1 depicts the ex-post payoffs of workers in sector $Y$ if they vote for trade-reform in the case with individual specific uncertainty, $V_{U}^{+}(c)$, and in the case without individualspecific uncertainty, $V_{C}^{+}(c)$. The figure also depicts the ex-post payoff of workers in sector $Y$ in the case trade-reform is rejected, $V^{*}$. It is assumed that workers in sector $Y$ with zero individual-specific cost of switching are ex-post better off with trade-reform; otherwise workers in sector $Y$ would always vote against trade-reform with or without individual-specific uncertainty. The reason why $V_{C}^{+}(c)$ lies below $V^{*}$ for large $c$ is that workers who stay in sector $Y$ are always worse off with trade-reform than without as the relative price of good $X$ increases. $V_{C}^{+}(c)$ lies above $V_{U}^{+}(c)$ for large $c$ because, in the 
case with individual-specific uncertainty, workers in sector $Y$ who vote for trade-reform will always incur the $\operatorname{cost} \theta$ to have the option of switching sector.

\section{Figure 1: Payoff With and Without Trade-Reform.}

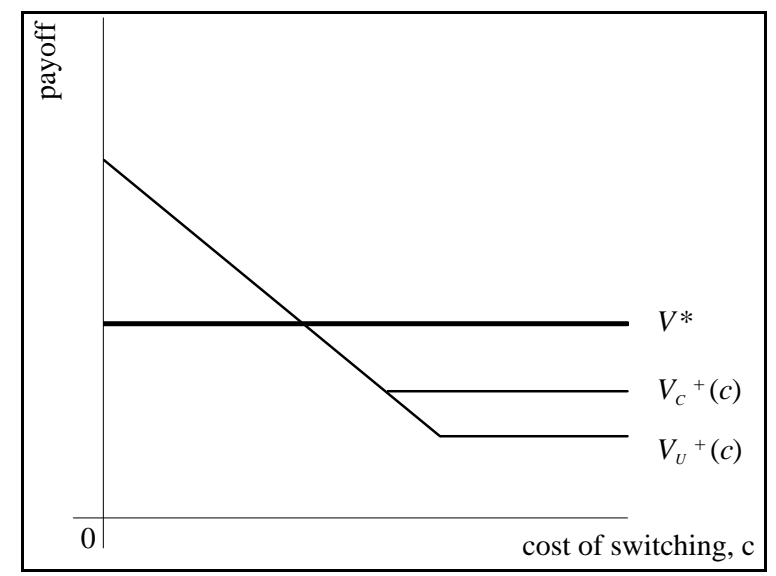

Notes: The convex function labeled $V_{C}^{+}(c)$ is the end-of-period payoff of workers initially in sector $Y$ as a function of the individual-specific cost of switching sectors $c$ if trade-reform is enacted and they know their individual-specific cost before trade-reform. The convex function labeled $V_{U}^{+}(c)$ is the end-of-period payoff of workers initially in sector $Y$ as a function of the individual-specific cost of switching sector if they are uncertain about their individual-specific cost before trade-reform and plan to incur $\theta$ after trade-reform is enacted.

FR show that in this static trade-model there is no status quo bias because: (I) while there are instances where trade-reform would pass without individual-specific uncertainty but not with individual-specific uncertainty; (II) there are also instances where trade-reform would pass with individual-specific uncertainty but not without individual-specific uncertainty. To understand (I), suppose that (3) is not satisfied. In this case, trade-reform will be rejected with individual-specific uncertainty if workers initially in sector $Y$ constitute a majority of all workers in the economy. However, trade-reform would pass without individual-specific uncertainty if workers in sector $Y$ for whom (5) holds combined with workers in sector $X$ constitute a majority of all workers in the economy. To understand (II), suppose that (3) is satisfied but that workers in sector $Y$ for whom (5) does not hold constitute a majority of all workers in the economy. In this case, trade-reform is rejected without individual-specific uncertainty but would pass with individual-specific uncertainty. The remaining question is whether (5) not holding for a majority of workers and (3) holding for workers in sector $Y$ are consistent. To see that they are suppose first that the distribution of $c_{i}$ is symmetric. In this case, the two conditions are consistent because the fact that workers in sector $Y$ can stay in sector $Y$ if individual-specific costs of switching turn out to be high implies that $V_{U}^{+}(c)$ is a strictly convex function of $c$. Hence, workers in sector $Y$ are effectively risk-loving and the expected value $E V_{U}^{+}(c)$ may be 
greater than $V^{*}$ although $V_{C}^{+}(c)<V^{*}$ for strictly more than half of the possible values of $c$, see Rothschild and Stiglitz (1970). Another reason why the two conditions are consistent is that the mean of the distribution of $c_{i}$ may be lower than the median (the distribution may be skewed to the left).

\subsection{The Two-Period Model}

In the static model there is no status quo bias introduced by individual-specific uncertainty as individual-specific uncertainty may lead to trade-reform being passed in instances where it would not have passed without it. FR therefore consider a two-period version of their trade-model to establish a status quo bias. In the two-period model, workers vote twice on trade-reform: in the beginning of the first period and, again, in the beginning of the second period. Trade-reform can be reversed costlessly and decisions are still made by majorityrule. Immediately after trade-reform has been enacted in the first period, workers decide on whether to incur the cost $\theta$ necessary to have the option of switching to sector $X$. Immediately after $\theta$ has been incurred, they decide on whether to also incur the individualspecific cost $c_{i}$ and go to work in sector $X$ during the first period. Workers who have switched to sector $X$ in the first period can costlessly switch back to sector $Y$ in the second period. Total labor income of workers consists of their wage in the first period and their wage in the second period. In the case without individual-specific uncertainty, all workers know their total cost of switching sector $\theta+c_{i}$ in the beginning of the first period. In the case with individual-specific uncertainty, they only know $\theta$ and the distribution of $c_{i}$ among workers in their sector in the beginning of the first period; they find out about $c_{i}$ only if trade-reform is passed and they incur $\theta$.

The possible equilibrium outcomes in the two-period model are: trade-reform is rejected in the first and in the second period (no trade-reform); trade-reform is passed in the first period and revoked in the second period (temporary trade-reform); and trade-reform is passed in the first period and not revoked in the second period (permanent trade-reform). ${ }^{7}$ The next table compares equilibrium outcomes with and without individual-specific uncertainty in the beginning of the first period.

Table 2: Trade-Reform in the Two-Period Model

\begin{tabular}{|l|l|}
\hline CERTAINTY & UNCERTAINTY \\
\hline Permanent Trade-Reform & $\begin{array}{l}\text { Permanent Trade-Reform/Temporary } \\
\text { Trade-Reform/No Trade-Reform }\end{array}$ \\
\hline No Trade-Reform & Permanent Trade-Reform/Temporary \\
\hline
\end{tabular}

\footnotetext{
${ }^{7}$ It is straightforward to show that it is impossible that trade-reform is rejected in the first period and passed in the second period.
} 
Notes: Permanent trade-reform refers to trade-reform being passed in the first period and not revoked in the second period. Temporary trade-reform refers to trade-reform being passed in the first period but revoked in the second. No trade-reform refers to trade-reform being rejected in both periods.

The first row of the table indicates that, considering all instances where under certainty there would be permanent trade-reform, there are some instances where individual-specific uncertainty in the beginning of the first period implies that trade-reform will be in place in the first but not in the second period (temporary trade-reform) as well as some instances where trade-reform will neither be in place in the first nor in the second period (no tradereform). The second row of the table states that considering all instances where under certainty there would be no trade-reform, there are some instances where individualspecific uncertainty implies that trade-reform will be in place in the first period only (temporary trade-reform) as well as some instances where trade-reform would be in place in the first and second period (permanent trade-reform). The first and second row of the table taken together yield that there may be permanent trade-reform with individual-specific uncertainty in cases it would have been rejected in both periods without and vice-versa. Hence, individual-specific uncertainty does not generate an asymmetry as defined by FR and there is no bias towards the status quo in the two-period trade-model.

The intuition for why there may be no trade-reform with individual-specific uncertainty in the beginning of the first period in instances where there would be a permanent trade-reform under certainty is analogous to the static model. The ex-ante expected payoff of workers in sector $Y$ from trade-reform may be lower than the payoff without trade-reform although many workers have a low individual-specific cost of switching. The other cases in the first row of the table are equally straightforward.

Understanding why there may be a permanent trade-reform with individual-specific uncertainty in the beginning of the first period in instances where there would be no tradereform under certainty is somewhat more complex. First, suppose that workers $i$ initially in sector $Y$ for whom

$$
(1+\delta) V^{*} \geq W_{C}^{+}\left(c_{i}\right)=v\left(P^{+}\right) \operatorname{Max}\left\{(1+\delta) w_{X}^{+}-c_{i}-\theta,(1+\delta) w_{Y}\right\}
$$

holds constitute a strict majority of all workers in the economy; $\delta \geq 0$ denotes the discount rate applied to second period payoffs and $V^{*}$ is defined in (2). In this case, trade-reform will be rejected in the first period and in the second period if there is no individual-specific 
uncertainty in the beginning of the first period. This is because (6) implies that permanent trade-reform makes a strict majority of workers worse off than no trade-reform. ${ }^{8}$

Second, suppose that

$$
\begin{aligned}
(1+\delta) V^{*} & \leq E W_{U}^{+}(c) \\
& =E v\left(P^{+}\right) \operatorname{Max}\left\{(1+\delta) w_{X}^{+}-c-\theta,(1+\delta) w_{Y}-\theta\right\}
\end{aligned}
$$

In this case, all workers in sector $Y$ will vote for trade-reform in the case with individualspecific uncertainty in the beginning of the first period if they believe that trade-reform will not be revoked in the second period if passed in the first period. ${ }^{9}$ Workers' beliefs that trade-reform, if passed in the first period, will not be revoked in the second period will be rational if workers in sector $Y$ who do not switch to sector $X$ in the first period (after trade-reform has been passed) are a minority, i.e. less than half of all workers in the economy. This is because all workers who work in sector $X$ at the end of the first period will support trade-reform in the beginning of the second period, independently of whether they have always been working in sector $X$ or whether they switched from sector $Y$.

Third, suppose that workers $i$ in sector $Y$ for whom

$$
(1+\delta) w_{X}^{+}-c_{i} \leq(1+\delta) w_{Y}
$$

holds are a minority. This implies that, if trade-reform has been enacted in the first period and workers believe that trade-reform will not be revoked in the second period, then workers who switch to sector $X$ plus workers already in sector $X$ will be a majority in the beginning of the second period. Workers' beliefs that trade-reform, if passed in the first period, will not be revoked in the second period are therefore rational if (8) holds. If the conditions associated with (6), (7), and (8) do not logically contradict each other, then there are instances where there will be a permanent trade-reform with individual-specific uncertainty in the beginning of the first period although there would have been no tradereform without individual-specific uncertainty. Hence, there is no status quo bias introduced by uncertainty in the two-period trade-model.

\footnotetext{
${ }^{8}$ The condition in (6) assumes implicitly that workers believe that trade-reform is not revoked in the second period if passed in the first period. It is demonstrated in the appendix, however, that the same condition implies that a majority of workers would vote against trade-reform even if they believed that trade-reform would be revoked in the second period if passed in the first.

${ }^{9}$ It is assumed that workers in sector $Y$ believe that if trade-reform is rejected in the first period then it will also be rejected in the second period. It is demonstrated in the appendix that (7) implies that workers in sector $Y$ would vote for trade-reform in the first period even if they believed that trade-reform would be accepted in the second period if rejected in the first period.
} 
To see that the three conditions do not logically contradict each other, it is useful to consider Figure 2. The first of the three conditions, that workers in sector $Y$ for whom (6) holds constitute a strict majority of all workers in the economy, corresponds to the assumption that workers in sector $Y$ with individual-specific cost above $c_{L}$ are more than half of the workers in the economy. The third condition, that workers in sector $Y$ for whom (8) holds constitute a minority, corresponds to the assumption that workers in sector $Y$ with individual-specific cost above $c_{U}$ are half or less of all workers in the economy. The figure also illustrates the second condition, $(1+\delta) V^{*} \leq E W_{C}^{+}(c)$. The reasons why $(1+\delta) V^{*}, W_{C}^{+}(c)$, and $W_{U}^{+}(c)$ lie the way illustrated in Figure 2 are detailed in the previous section before Figure 1.

\section{Figure 2: Trade-Reform in the Two-Period Model}

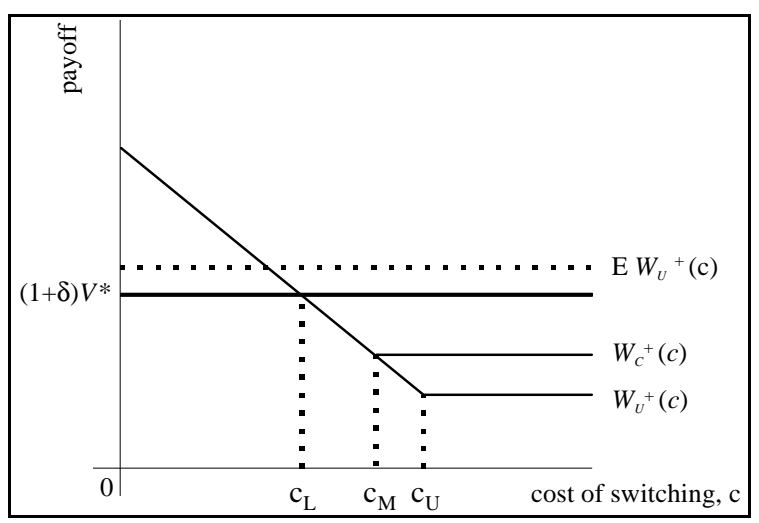

Notes: The three conditions in the text illustrated. Workers with costs of switching above $c_{U}\left(c_{L}\right)$ are a minority (majority) of all workers in the economy. In this case, not enough workers support trade-reform with certainty about individual-specific costs in the beginning of the first period. But, with individual-specific uncertainty in the beginning of the first period, trade-reform is passed in the first period and not revoked in the second period if workers believe that trade-reform will not be revoked in the second period if passed in the first period.

It is straightforward to see why the second condition is consistent with the third condition: the smaller the number of people with high individual-specific switching-costs, the higher the expected value from trade-reform for workers in sector $Y$. The reason why the second condition is also consistent with the first condition is analogous to the static model. First consider the case where the distribution of $c_{i}$ is symmetric. In this case, the two conditions are consistent because the fact that workers in sector $Y$ can stay in sector $Y$ if individual-specific costs of switching turn out to be high implies that $W_{U}^{+}(c)$ is a strictly convex function of $c$. Hence, workers in sector $Y$ are effectively risk-loving with respect to trade-reform when they face individual-specific uncertainty at the time they vote. 
Another reason why the two conditions are consistent is that the distribution of $c$ may be skewed to the left. ${ }^{10}$

The more difficult question is, are the first and third condition consistent? To put it differently, why would some workers in sector $Y$ go to work in sector $X$ in the first period after they find out about their individual-specific switching-cost although they would have voted against enacting trade-reform had they know their switching-cost. There are two reasons:

(I) The first reason operates even if the cost of having the option of switching $\theta$ is zero (and hence workers have not incurred any sunk cost at the time they have to decide whether to switch sector). Workers in sector $Y$ who vote against trade-reform in the beginning of the first period if there is no individual-specific uncertainty do so because they are better off in sector $Y$ at before-trade-reform prices than in sector $X$ at after-tradereform prices once they take into account their cost of switching. Workers in sector $Y$ who switch to sector $X$ once trade-reform has been passed in the first period do so because they are better of in sector $X$ at after-trade-reform prices that in sector $Y$ at after-tradereform prices. As relative prices change in favour of sector $X$ after trade-reform is enacted, there are workers in sector $Y$ who go to work in sector $X$ if trade-reform is passed in the first period although they would have voted against enacting trade-reform had they know their cost in the beginning of the first period.

(II) The second reason is simpler. Workers in sector $Y$ who vote against trade-reform in the beginning of the first period if there is no individual-specific uncertainty do so because they are better off in sector $Y$ at before-trade-reform prices than in sector $X$ at aftertrade-reform prices taking into account their total cost of switching $\theta+c_{i}$. The decision to switch sector is, however, based on the individual-specific cost of switching $c_{i}$ only as the cost of having the option of switching $\theta$ is assumed to be sunk. Hence, if the cost of having the option of switching sector $\theta$ is strictly positive, then there is an additional reason why some workers in sector $Y$ go to work in sector $X$ in the first period if tradereform is passed although they would have voted against enacting trade-reform had they know their switching-cost.

A fourth condition needs to be satisfied for the equilibrium where trade-reform is enacted in the first period and not revoked in the second period in the case with individualspecific uncertainty in the beginning of the first period to the unique equilibrium in

\footnotetext{
${ }^{10}$ The argument to establish that there are some instances where there will be a temporary trade-reform with individual-specific uncertainty in the beginning of the first period although there would be no tradereform without individual-specific uncertainty is straightforward and therefore omitted.
} 
instances where trade-reform would be rejected in both period under certainty. This condition is that workers $i$ in sector $Y$ for whom

$$
w_{X}^{+}-c_{i} \leq w_{Y}
$$

holds are a minority. In this case, if workers in sector $Y$ support trade-reform in the beginning of the first period in the case with individual-specific uncertainty, then they must necessarily believe that trade-reform will not be revoked in the beginning of the second period. To see this note first that workers initially in sector $Y$ will always incur $\theta$ if they voted for enacting trade-reform in the beginning of the first period. Hence, their decision of changing sector is based on the individual-specific cost of switching only. Once they have incurred $\theta$ their net gain of switching to sector $Y$ is equal to $w_{X}^{+}-c_{i}-w_{Y}$ if they believe that trade-reform will be revoked in the second period. Hence, the condition in (9) implies that if trade-reform is enacted, then workers who stay in sector $Y$ in the first period and vote against trade-reform in the beginning of the second period will be a minority, even if all workers were to believe that trade-reform would be revoked in the second period. Consequently, it would be irrational for workers in sector $Y$ to support trade-reform in the beginning of the first period and at the same time believe that trade-reform will be revoked in the beginning of the second period.

\section{$4 \quad$ Summary}

Can individual-specific uncertainty lead to a bias against efficiency-enhancing economic policies? The first point made in this paper is that individual-specific uncertainty may increase the chances of policies benefiting a majority ex-post being rejected ex-ante. This is true, however, whether these economic policies increase or decrease aggregate efficiency. Individual-specific uncertainty may therefore decrease the probability that efficiencyenhancing policies are enacted but, at the same time, increase the probability that enacted policies are efficiency-enhancing. The main point made in the paper is that individualspecific uncertainty can actually strictly increase the chances of a permanent trade-reform in FR's dynamic trade-model. The reason is that trade-reform, once enacted, may not be revoked in future elections (when workers no longer face any individual-specific uncertainty) even if trade-reform would not have been enacted in the first place without individual-specific uncertainty. This is because trade-reform increases the relative price of the good produced in the sector gaining from reform. Some workers will therefore go to work in the sector that gains once reform has been passed and uncertainty has been resolved (even if they have not incurred any sunk cost), although they would have voted against enacting trade-reform in the first place had there been no uncertainty. These 
workers will vote against revoking trade-reform in future elections. This argument generalizes to voting on any type of reform. In a realistic setting, reform will increase the incentives of agents to move into those economic activities that have benefited from the new economic policies. Some agents will therefore move into these economic activities once reform has been passed, even if they would have voted against reform without individual-specific uncertainty. Hence, support in favor of sustaining reform once individual-specific uncertainty has been resolved will be greater than support for enacting reform if there is no individual-specific uncertainty. Individual-specific uncertainty may therefore increase the chances of permanent reform. 


\section{References}

Brainard, S. Lael and Thierry Verdier (1994), "Lobbying and Adjustment in Declining Industries," European Economic Review, Volume 38, Number 4, April.

Coate, Stephen, and Stephen Morris (1999), "Policy Persistence," American Economic Review, Volume 89, Number 5, December.

Fernandez, Raquel and Dani Rodrik (1991), "Resistance to Reform: Status Quo Bias in the Presence of Individual-Specific Uncertainty," American Economic Review, Volume 81, Number 5, December.

Rodrik, Dani (1991), "Policy Uncertainty and Private Investment in Developing Countries, Journal of Development Economics, Volume 36, Number 2, October.

Rothschild, Michael and Joseph Stiglitz (1970), "Increasing Risk: Definition," Journal of Economic Theory, Volume 1, Number 1, January.

The American Heritage Dictionary of the English Language, $4^{\text {th }}$ Edition, Boston: Houghton Mifflin, 2000. 


\section{Appendix}

(A1) Proof that workers will vote against enacting trade-reform in the beginning of the first period without individual-specific uncertainty if workers in sector $Y$ for whom (6) holds are more than half of all workers in the economy even if they believe that trade-reform, if passed in the first period, will be revoked in the second period.

In this case, the payoff of workers in sector $Y$ with individual-specific cost $c_{i}$ in the beginning of the first period, if trade-reform is passed, is

$$
v\left(P^{+}\right) \operatorname{Max}\left\{w_{X}^{+}-c_{i}-\theta, w_{Y}\right\}+\delta V^{*} .
$$

If workers in sector $Y$ for whom (6) holds constitute a majority of all workers in the economy, then workers in sector $Y$ for whom (A1) is smaller than $(1+\delta) V^{*}$ are also a majority. This is because (6) implies that $V^{*} \geq v\left(P^{\top}\right) \operatorname{Max}\left\{w_{X}^{\top}-c_{i} /(1+\delta)-\theta /(1+\delta), w_{Y}\right\}$ and hence, because $\delta \geq 0$, that $V^{*} \geq v\left(P^{+}\right) \operatorname{Max}\left\{w_{X}^{+}-c_{i}-\theta, w_{Y}\right\}$.

(A2) Proof that workers in sector $Y$ will vote for trade-reform in the beginning of the first period with individual-specific uncertainty if (7) holds even if they believe that tradereform, if rejected in the first period, will be passed in the second period.

In this case, the ex-ante payoff for workers in sector $Y$ if trade-reform is rejected in the first period is

$$
V^{*}+\delta \operatorname{Max}\left\{E v\left(P^{+}\right) \operatorname{Max}\left\{w_{X}^{+}-c_{i}-\theta, w_{Y}-\theta\right\}, v\left(P^{+}\right) w_{Y}\right\} .
$$

This is because they will only pay $\theta$ in the second period if the expected payoff in the beginning of the second period from switching into sector $X$ is greater than the payoff from staying in sector $Y$. To see that (7) implies that (A2) is smaller than $\operatorname{Ev}\left(P^{+}\right) \operatorname{Max}\left\{(1+\delta) w_{X}^{+}-c_{i}-\theta,(1+\delta) w_{Y}-\theta\right\}$ it is useful to distinguish two cases.

(I) The first case is $E v\left(P^{+}\right) \operatorname{Max}\left\{w_{X}^{+}-c_{i}-\theta, w_{Y}-\theta\right\}<v\left(P^{+}\right) w_{Y}$. This implies $\operatorname{Ev}\left(P^{+}\right) \operatorname{Max}\left\{w_{X}^{+}-c_{i}-\theta, w_{Y}-\theta\right\} \leq V^{*}$ and hence that (A2) is smaller than $(1+\delta) V^{*}$. Combined with (7) this yields the result.

(II) The second case is $E v\left(P^{+}\right) \operatorname{Max}\left\{w_{X}^{+}-c_{i}-\theta, w_{Y}-\theta\right\} \geq v\left(P^{+}\right) w_{Y}$. In this case (7) implies that (A2) is smaller than

$$
\begin{aligned}
& E v\left(P^{+}\right) \operatorname{Max}\left\{w_{X}^{+}-c_{i} /(1+\delta)-\theta /(1+\delta), w_{Y}-\theta /(1+\delta)\right\} \\
& +\delta E v\left(P^{+}\right) \operatorname{Max}\left\{w_{X}^{+}-c_{i}-\theta, w_{Y}-\theta\right\}
\end{aligned} .
$$

(A3), and therefore (A2), is smaller than

$$
\begin{aligned}
& E v\left(P^{+}\right) \operatorname{Max}\left\{(1+\delta) w_{X}^{+}-c_{i}-\theta,(1+\delta) w_{Y}-\theta\right\} \\
& =(1+\delta) E v\left(P^{+}\right) \operatorname{Max}\left\{w_{X}^{+}-c_{i} /(1+\delta)-\theta /(1+\delta), w_{Y}-\theta /(1+\delta)\right\}
\end{aligned}
$$

because $\delta \geq 0$ implies 


$$
\begin{aligned}
& E v\left(P^{+}\right) \operatorname{Max}\left\{w_{X}^{+}-c_{i}-\theta, w_{Y}-\theta\right\} \\
& \leq E v\left(P^{+}\right) \operatorname{Max}\left\{w_{X}^{+}-c_{i} /(1+\delta)-\theta /(1+\delta), w_{Y}-\theta /(1+\delta)\right\}
\end{aligned}
$$

